\title{
Chemical Contamination Sensor for Phosphate Ester Hydraulic Fluids
}

\author{
Sumit Paul, ${ }^{1}$ Wolfgang Legner, ${ }^{1}$ Angelika Krenkow, ${ }^{1}$ Gerhard Müller, ${ }^{1}$ Thierry Lemettais, $^{2}$ \\ Francois Pradat, ${ }^{2}$ and Delphine Hertens ${ }^{3}$
}

\author{
${ }^{1}$ EADS Innovation Works, 81663 München, Germany \\ ${ }^{2}$ EADS Innovation Works, 92152 Suresnes Cedex, France \\ ${ }^{3}$ Airbus Operations S.A.S., 31300, Toulouse, France
}

Correspondence should be addressed to Sumit Paul, sumit.paul@eads.net

Received 22 December 2009; Accepted 16 April 2010

Academic Editor: Hui Hu

Copyright (c) 2010 Sumit Paul et al. This is an open access article distributed under the Creative Commons Attribution License, which permits unrestricted use, distribution, and reproduction in any medium, provided the original work is properly cited.

\begin{abstract}
The paper deals with chemical contamination monitoring in phosphate-ester-based hydraulic fluids using nondispersive infrared (NDIR) optical absorption. Our results show that NDIR monitoring allows detecting the take-up of water into such fluids and their hydrolytic disintegration as these become additionally stressed by Joule heating. Observations on the O-H stretching vibration band (3200-3800 $\left.\mathrm{cm}^{-1}\right)$ are used for determining the free water content $(0-1.5 \%)$ and the Total Acid Number $(0-1 \mathrm{mgKOH} / \mathrm{g})$. Both quantities can be assessed by monitoring the strength and the asymmetry of the $\mathrm{O}-\mathrm{H}$ vibration band with regard to the free water absorption band centred around $3500 \mathrm{~cm}^{-1}$. As such optical parameters can be assessed without taking fluid samples from a pressurised hydraulic system, fluid degradation trends can be established based on regular measurements, before irreversible damage to the fluid has occurred. Therefore maintenance actions can be planned accordingly, which is very important for the airline, as unscheduled maintenance disturbs the flights organisation and often generates money loss.
\end{abstract}

\section{Introduction}

AVIATION hydraulic fluids based on phosphate-esters are hygroscopic [1] and, moreover, their chemical properties are highly dependent on operation conditions. As a result, their lifetime is highly unpredictable. The performance of the entire aircraft hydraulic system is affected by the condition of the hydraulic fluid and if chemical degradation goes undetected, it may cause downstream mechanical damage to the hydraulic system itself and to its consumers such as flight controls, the landing gear, and the braking system [2]. The damage may be economic at best or catastrophic at worst. At present, assessing the condition of the hydraulic fluid in an aircraft is laborious, time-consuming, and expensive. Therefore the fluid is typically tested less than once a year with the risk of unscheduled maintenance if the fluid has exceeded its limits of usage. Consequential interruption of the airline service bears a huge economic cost.

The current state of the art in aircraft maintenance is that hydraulic fuel testing is carried out off-line. "Off-line" meaning that the hydraulic system needs to be tapped using a dedicated sampling valve, fluid samples to be taken and sent to dedicated laboratories for off-site analysis. Time to get analysis results is typically a few days. Maintenance actions in this case can only be taken after several days of delay.

This situation can be ameliorated in case on-line measurements become possible. "On-line" in this case means that the hydraulic system needs not to be tapped and that the results of a measurement are available on-site immediately. Performing measurements of relevant fluid properties onboard and repeating such measurements on a daily or weekly basis, as, for instance, before take-off or after landing, a degradation trend can be established and a time limit may be estimated after which maintenance actions need to be taken. With this knowledge of the fluid health evolution, and useful fluid lifetime, maintenance actions on the hydraulic fluid can be strategically scheduled that is, made to coincide with other necessary maintenance actions. In this way unscheduled maintenance is avoided and a higher level of aircraft availability is ensured. 


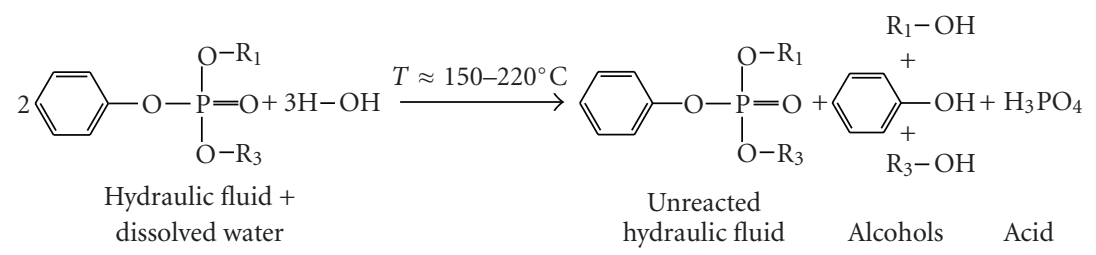

Conventional acid-base reaction within dissolved water:

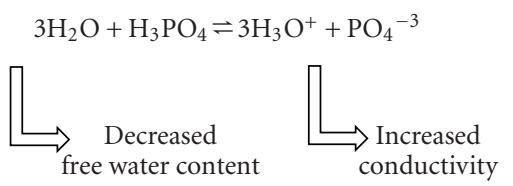

FIGURE 1: Chemical reactions following the take-up of water into a phosphate-ester based hydraulic fluid.

\section{Fluid Parameters of Interest}

The fluid parameters of interest to be monitored are as follows.

(a) Water Content. Due to their hydrophilicity water vapour can become dissolved in all kinds of phosphate-ester-based hydraulic fluids. Such "free water" can freeze and produce blockages and thus cause mechanical damage inside pumps and actuators [3].

(b) Acidity. Under conditions of thermal agitation, "free water" can react with phosphate-ester-based fluids by means of hydrolysis [4]. Upon disintegration of the base fluid, various kinds of alcohols are formed alongside with phosphorus acid molecules [5]. The phosphorus acid molecules, in turn, may dissociate in the remaining dissolved water and form phosphoric acid, which is corrosive and likely to inflict damage on metallic equipment being part of the hydraulic system, and seals. Especially, such corrosion damage can have adverse consequences if it occurs on the sharp edges of tightly fitting parts inside hydraulic actuators. The dissolved alcohols, on the other hand, can form gas bubbles and thus compromise the functioning of some equipment (cavitation). For these reasons, acidity is the key parameter that defines fluid life.

In the following we present evidence that it is possible to assess the take-up of water (parameter (a)) and the subsequent hydrolysis of the base fluid and the concomitant generation of acidity (parameter (b)) as the fluid becomes additionally exposed to Joule heating. We further show that both parameters can be assessed with the help of a nondispersive infrared (NDIR) sensor system through optical windows, that is, without tapping fluid from a pressurised hydraulic system.

\section{Sensor Operation Principle}

3.1. Fluid Degradation Mechanism. The importance of the above degradation parameters reveals from the fact that phosphate-ester fluids are polar and that they thus tend to absorb water. Dissolved water in turn can cause disintegration of the phosphate-ester molecules proceeding along three different reaction pathways: oxidation, pyrolysis, and hydrolysis. The phosphateesters themselves can form strong acids (Phosphate Ester $+\mathrm{H}_{2} \mathrm{O} \rightarrow$ Alcohol $+\mathrm{H}_{3} \mathrm{PO}_{4}$ ). The generation of alcohols influences the force-transmitting properties of the fluid, and can thus affect the functioning of some of the equipment. Phosphorus acid molecules, on the other hand, can interact with dissolved water to form $\mathrm{H}_{3} \mathrm{O}^{+}$ ions, which may induce corrosion.

The hydrolysis of a phosphate-ester-based fluid is schematically illustrated in Figure 1. It indicates that, in addition to water, acidity formation also requires a significant amount of thermal agitation.

3.2. Infrared Absorption Monitoring of the Reaction Pathway. Careful consideration of Figure 1 reveals that in this degradation interaction the number of $\mathrm{O}-\mathrm{H}$ bonds is conserved. A second point to note is that the $\mathrm{O}-\mathrm{H}$ groups are initially associated with water and after hydrolysis with various kinds of alcohols or with phosphorus acid. A third interesting point is that these different kinds of $\mathrm{O}-\mathrm{H}$ groups are distinguishable on account of their specific infrared (IR) absorption characteristics [6-11]. At their normally pure state, phosphate ester hydraulic fluids should not show any $\mathrm{O}-\mathrm{H}$ absorption feature. A broad $\mathrm{O}-\mathrm{H}$ feature, centred around $3500 \mathrm{~cm}^{-1}$, however, is observed in liquid water. Alcohols, on the other hand, exhibit $\mathrm{O}-\mathrm{H}$ absorption features low-frequency-shifted towards smaller wave numbers. This is specifically the case for butanol and phenol, that is, typical disintegration products of phosphate esters. This discussion suggests that the presence of "free water" as well as of hydrolysis products may both be detectable and distinguishable by monitoring the intensity and the spectral distribution of the $\mathrm{O}-\mathrm{H}$ absorption feature within the wave number range extending from $3100 \mathrm{~cm}^{-1}$ to $3700 \mathrm{~cm}^{-1}$.

3.3. Optical Monitoring of Chemical Changes in Water Contaminated and Thermally Treated Skydrol LD-4. Following the above ideas, a series of experiments was performed to assess the infrared absorption characteristics of Skydrol LD4 , that is, a widely used aviation hydraulic fluid. Samples in 


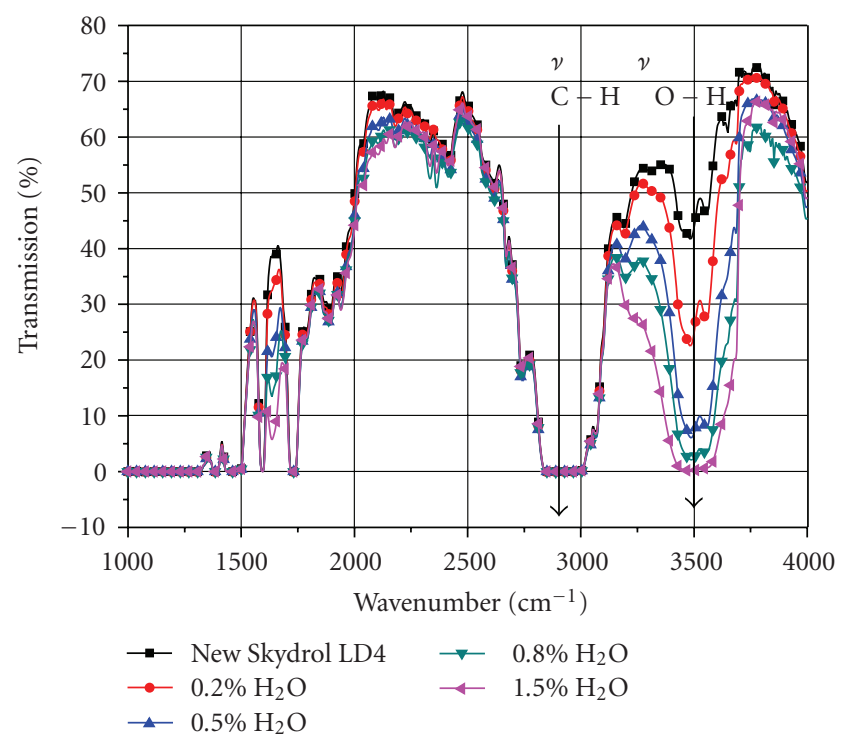

FIGURE 2: IR transmission spectra of pure and water-contaminated samples of Skydrol LD4.

their nominally pure state, after addition of various amounts of water and after performing additional heat treatments were examined. In this way it was attempted to arrive at a set of optical features that allow the state of contamination and degradation to be assessed by purely optical means.

As a first result we present in Figure 2 Fourier Transform Infrared (FTIR) spectra of water-contaminated samples of Skydrol LD-4. This picture shows that water addition is associated with a strong and continuous increase in the $\mathrm{OH}$ absorption band centred around $3500 \mathrm{~cm}^{-1}$.

The data of Figure 2 clearly reveal that the dissolved water content in Skydrol LD-4 can easily be determined from changes in the optical transmission at $3500 \mathrm{~cm}^{-1}$. The optical path length in this case was $0.2 \mathrm{~mm}$, that is, a narrow gap. Titration of these water contaminated samples further revealed that such fluids are not acid. Neutralisation in each case was obtained with less than $0.1 \mathrm{mg} \mathrm{KOH} / \mathrm{g}$.

In a hydraulic system Joule heat is generated when the fluid is pressed through the many narrow constrictions inside hydraulic actuators [12]. In order to simulate such a situation, the above fluid samples were boiled at $200^{\circ} \mathrm{C}$ for 8 hours in glass flasks with tightly fitting glass seals. These boiling temperatures, which are above the normal range of fluid operation temperatures, had been used to accelerate acidity generation in our laboratory tests. After heat treatment the same set of measurements, that is, IR absorption measurements as well as titrations for TAN values were repeated.

The effect of heat treatment on the water absorption line at around $3500 \mathrm{~cm}^{-1}$ is shown in Figure 3. Spectra a and b represent the state before heat treatment. Spectra $c$, d, and e, on the other hand, show what happens when the same fluid samples are subjected to an additional heat treatment. TAN values in this latter case have been raised into the range between 1 and $2 \mathrm{mg} \mathrm{KOH} / \mathrm{g}$. In the case of dissolved water (a,

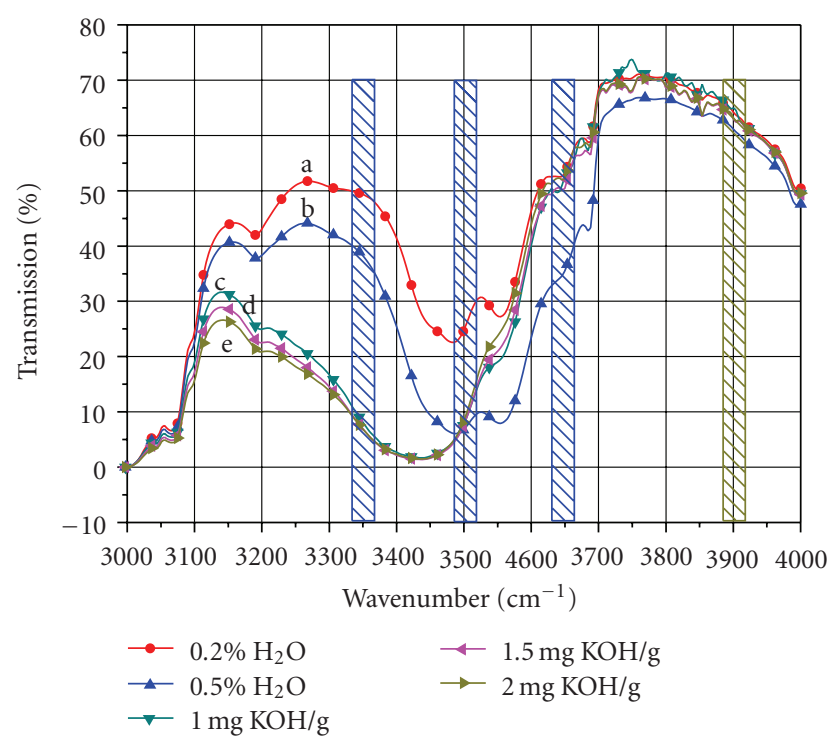

FIGURE 3: IR transmission of water-contaminated and heat-treated Skydrol LD4, a, b after addition of increasing amounts of water, c, $\mathrm{d}$, e after additional heat treatment leading to acidification. Optical path length: $0.2 \mathrm{~mm}$.

b) the $\mathrm{O}-\mathrm{H}$ absorption feature is more or less symmetric with respect to the $3500 \mathrm{~cm}^{-1}$ water absorption line, independent of the water content that had been added. In the second case (c, d, e), when there was an additional input of heat, the $\mathrm{O}-\mathrm{H}$ absorption feature is clearly red-shifted towards lower photon energies. Additionally, the symmetry around $3500 \mathrm{~cm}^{-1}$ is clearly destroyed in this case.

The three bars in the centre of Figure 3 represent the three measurement windows from which we want to determine the fluid quality and the fourth, the rightmost bar, represents a reference window. Extensive tests have shown that in this latter spectral window the optical transmission (Tr) of the fluids is not influenced by any of the chemical changes in the fluid. This latter window can therefore be used to monitor the transparency of the sapphire windows in the NDIR sensor discussed below as well as the brightness of the IR source:

$$
\begin{aligned}
C_{\mathrm{H}_{2} \mathrm{O}} & =f\left\{\operatorname{Tr}\left(3500 \mathrm{~cm}^{-1}\right)\right\}, \\
\mathrm{TAN}=f\{\Delta \operatorname{Tr}\} & =f\left\{\operatorname{Tr}\left(3650^{-1}\right)-\operatorname{Tr}\left(3350^{-1}\right)\right\} .
\end{aligned}
$$

\section{Checks on the Sensing Mechanism}

In order to reveal the reason for the red-shift of the O$\mathrm{H}$ absorption feature, FTIR measurements were performed on samples of Skydrol LD-4 to which butanol and phenol had been deliberately added. These two kinds of alcohols are known to be main decomposition products of Skydrol hydrolysis. For comparison, additional fluid samples were prepared to which both alcohol and water were added. A result obtained on these latter kinds of fluid is shown in Figure 4. These latter data clearly show that increasing phenol additions produce an increasing $\mathrm{O}-\mathrm{H}$ absorption at 


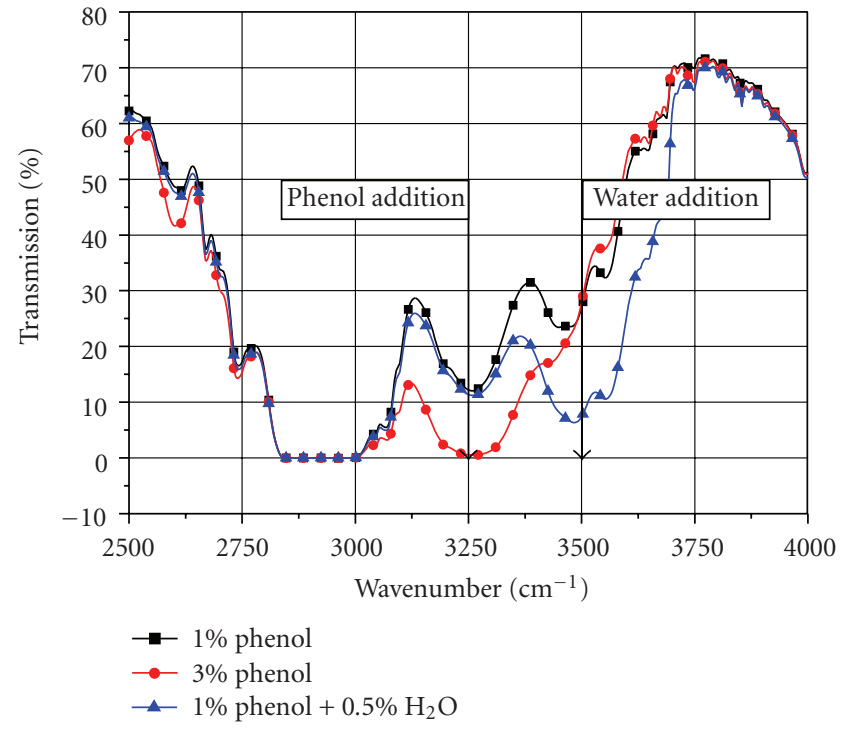

FIGURE 4: IR transmission of Skydrol LD-4 with different additions of phenol and a mixture of phenol and water. Optical path length: $0.2 \mathrm{~mm}$.

around $3250 \mathrm{~cm}^{-1}$. In comparison, additions of both water and phenol produce a double-peak structure with a first absorption peak at around $3500 \mathrm{~cm}^{-1}$ and a second one at around $3250 \mathrm{~cm}^{-1}$. As the additional water dilution does reduce the TAN as revealed from titration but leave the phenol $\mathrm{O}-\mathrm{H}$ absorption feature intact, it is clear that IR absorption measures the presence of hydrolysis products which had been produced in the acidification process rather than the acidity itself.

This same conclusion was further emphasized by an experiment in which we had added fresh water to an acid fluid sample (not shown in the figure). Deliberate additions of new water left the low wave number part of the $\mathrm{O}-\mathrm{H}$ absorption feature largely unaffected, but added significant spectral weight on the high wave number side. This unreacted water had a clear impact on the TAN of the fluid as the dissolved acid was diluted by the fresh water, not, however, on the presence or absence of hydrolysis products that had been generated in the preceding heat treatment. The spectroscopic data, therefore, do provide clues to the actual amount of free water that can still be removed by filtration and to the total number of hydrolysis products that had been generated up to the point of measurement.

\section{Optical Absorption Mapping of Other Hydraulic Fluids}

In the experiments reported above, low-density Skydrol LD4 had exclusively been used. In addition to that, a whole number of other phosphate-ester based fluids have been qualified for aircraft use. In aircraft operation also mixtures of those fluids may be used. A relevant question therefore is whether the method of optical transmission mapping, which had been developed for Skydrol LD-4, can also be applied to this larger group of fluids and possibly to mixtures thereof. Attempting to answer this question, the same range of measurements was repeated on samples of HyJet IV, HyJet A+, and Skydrol 500B-4. In the following we will briefly discuss the chemistry of these fluids and we will show that these exhibit strikingly similar IR spectra.

5.1. Chemistry of Aircraft Hydraulic Fluids. Fire-resistant hydraulic fluids mainly consist of neutral tri-alkylphosphates, tri-aryl-phosphates, and mixtures of alkylaryl-phosphates [13]. Alkyl groups are mainly formed with a chain length of C4-C10 (e.g., tri-butyl phosphate). In alkyl-aryl-phosphates alkyl-groups are partially substituted by phenyl-groups until eventually purely aromatic arylphosphates are obtained.

Whereas the phosphate nucleus largely determines the fire resistance of the fluid, the other physico-chemical properties are mainly determined by the hydrocarbon sidegroups. The ratio of the alkyl- and aryl-groups, in particular, determines the average molecular weight, the specific gravity and the viscosity of the base fluid. Mixed aryl-alkyl phosphates are used in the aviation industry as they improve both the low temperature properties of the base fluid as well as their high-temperature stability [14]. Commercial aviation hydraulic fluid base stocks mainly consist of mixtures of tributyl phosphate, di/-butyl phenyl phosphate and triphenyl phosphate (Figure 5) $[15,16]$, with the mixing ratio depending on the specific kind of application.

The above constituents make up roughly $99 \%$ of the fluid. Aviation hydraulic fluids, in addition, contain around $1 \%$ additives [17]. These additives include antioxidants, antiwear- and viscosity index improvers, and also minor amounts of metal deactivators and dyes [18].

5.2. Artificially Contaminated Fluid Samples. In Figure 6 we present the IR spectra of a range of different phosphateester fluids both in their nominally pure and in their water-contaminated states. It shows that both data sets are remarkably similar. The two outstanding features in all kinds of fluids are a very strong $\mathrm{C}-\mathrm{H}$ vibration line at around $2900 \mathrm{~cm}^{-1}$ and an $\mathrm{O}-\mathrm{H}$ vibration line at around $3500 \mathrm{~cm}^{-1}$. Whereas the first line is intrinsic to the fluids, the strength of the second line depends on the amount of water that had been added. The strength of this second line only depends on the amount of water added and only very little on the kind of the base fluid that had been used for soaking up the water. Considering the $3500 \mathrm{~cm}^{-1}$ water absorption feature we note that differences are very marginal at around $3500 \mathrm{~cm}^{-1}$ and moderate in their respective high- and low-energy wings. Similar data have been observed on the same range of fluid samples contaminated with other water concentrations.

Transmission spectra of Hyjet $\mathrm{V}$ with different acid and phenol contamination are presented in Figure 7. If we compare this figure with Figures 3 and 4, it becomes clear that both fluids exhibit closely similar transmission spectra and that both behave in a very similar manner when they are heat-treated or when alcohols are added. Again hydrolysis 


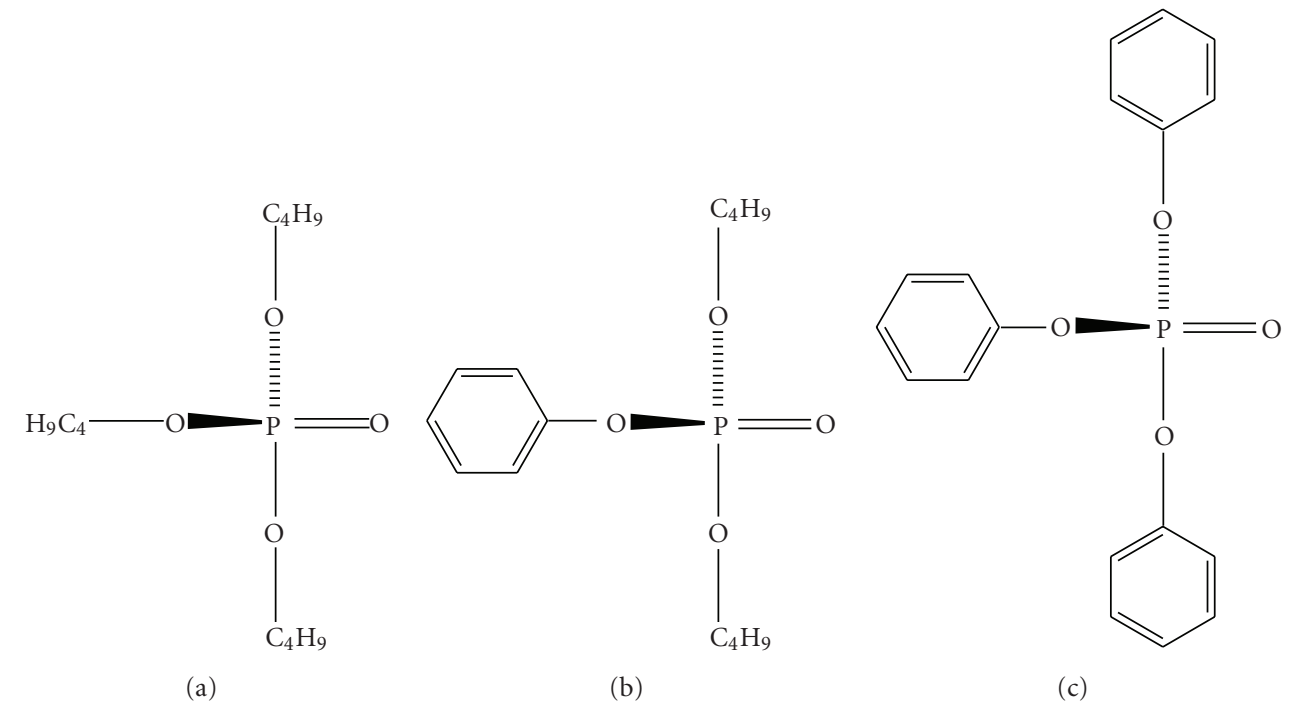

Figure 5: Chemical structure of constituents of aircraft certified hydraulic fluids. (a) Tri-butyl phosphate, (b) di-butyl phenyl phosphate, (c) tri-phenyl phosphate.

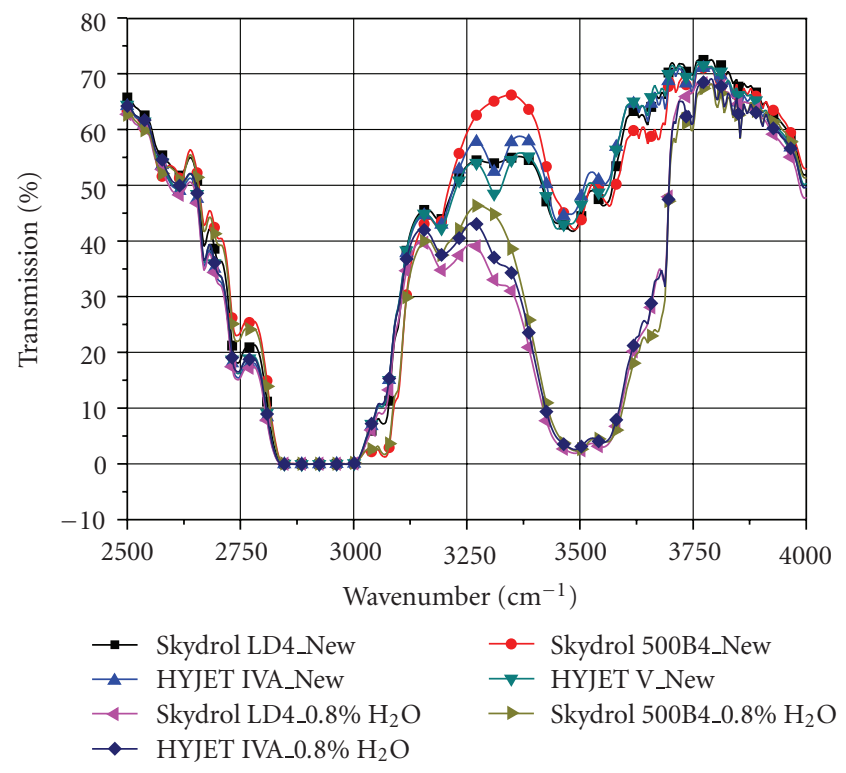

FIGURE 6: IR spectrum of different hydraulic fluids in their nominally pure state and the same fluids after addition of $0.8 \%$ water. Optical path length: $0.2 \mathrm{~mm}$.

induces the same kind of low-frequency shift of the O$\mathrm{H}$ absorption feature. Phenol additions confirmed that the $\mathrm{O}-\mathrm{H}$ shift is related to the same cause as in Skydrol LD4 (Figure 4), that is, formation of free alcohols.

\section{Demonstrator Sensor System}

In order to demonstrate the usefulness of the above described IR transmission mapping procedures, a demonstrator sensor system was built. The principle architecture of this sensor system is displayed in Figure 8.

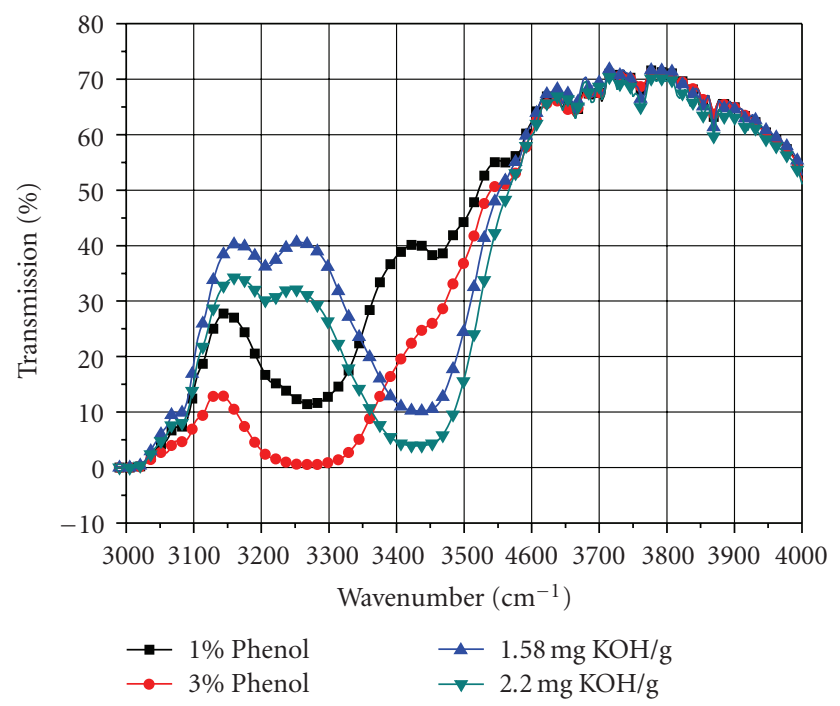

Figure 7: FTIR spectra of acid/phenol contaminated HyJet V. Optical path length: $0.2 \mathrm{~mm}$.

The fluid to be tested is passed through an optical absorption path that is limited on both sides by IR-transparent sapphire windows. On the left-hand side, pulsed IR radiation is produced by a broadband $(1-10 \mu \mathrm{m})$ MEMS thermal IR emitter from Intex Inc. Thermal emitters are low cost, robust, and simple IR sources [19]. The IR radiation is passed through the liquid and detected on the other side by a thermopile detector array produced by Micro Hybrid Electronic $\mathrm{GmbH}$. The Bi-Sb thermopiles are well known as highsensitivity wide-band IR detectors [20]. Thermopiles exhibit good linearity, require no optical chopper, no electrical bias and can operate over a broad temperature range [21]. The four detectors in this array are fitted with narrow-band-pass IR filters with centre wavelengths as indicated in Figure 8. 


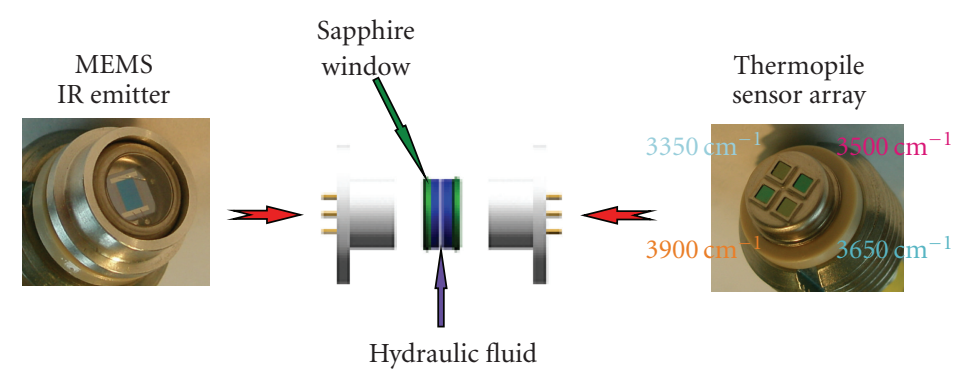

FIGURE 8: Schematics of IR detection system consisting of an MEMS-based IR emitter (left), an optical path (middle) and a 4-thermopile IR sensor array (right).
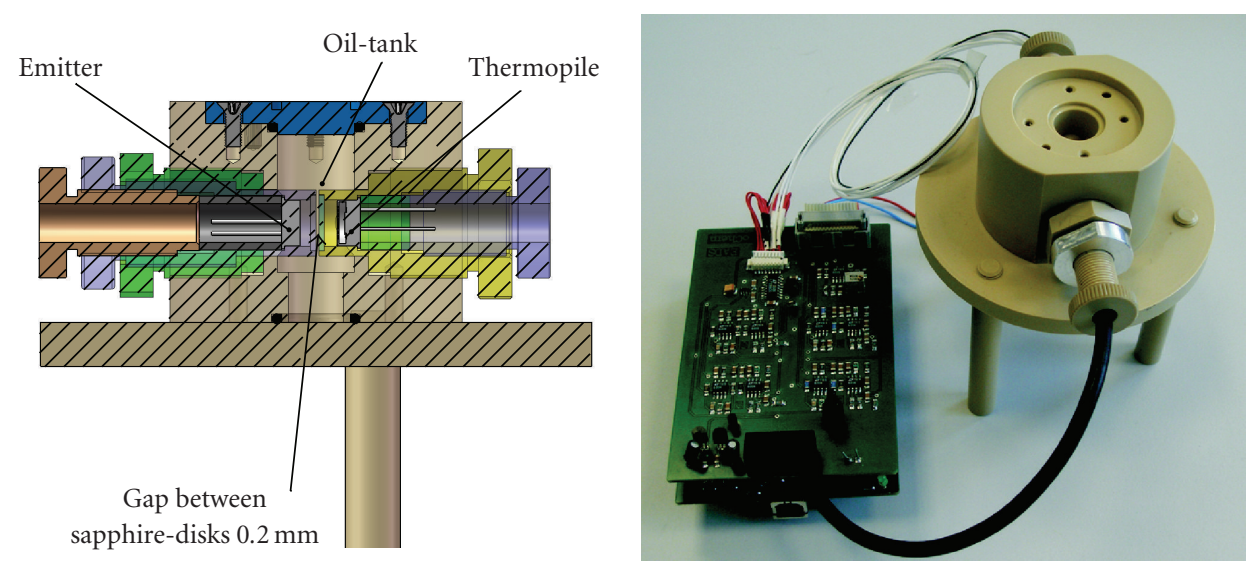

FIGURE 9: IR sensor system as integrated into a piece of piping: (left) Schematics, (right) realised sensor system.

Following the ideas explained earlier, three of these spectral windows embrace the $\mathrm{OH}$-absorption features in the fluid and the fourth is a reference window. The centre wavelengths of the optical filters, supplied by Jenoptik AG, deviated a little bit from the wave numbers indicated in Figure 8 (i.e., $3875 \mathrm{~cm}^{-1}, 3663 \mathrm{~cm}^{-1}, 3480 \mathrm{~cm}^{-1}$, and $3322 \mathrm{~cm}^{-1}$ ). Special care was taken in the assembly of the thermopile arrays to avoid cross-talk between the individual channels. The crosstalk of each channel to its three neighbour channels was less than $2 \%$.

The mechanical setup of this sensor system is shown in Figure 9. This small sensor vessel consists of highperformance thermoplastic Polyaryl-Ether-Ether-Ketone (PEEK) [22]. It can be filled with a few $\mathrm{mL}$ of fluid and its transparency can be tested by monitoring the transmission of the IR light across a $0.2 \mathrm{~mm}$ fluid channel that is generated by the two adjacent sapphire windows. The sensor electronics is realized on two printed circuit boards which contain the emitter driver and the detector electronics. A commercial USB data acquisition board was used to interface the sensor system to a PC with a dedicated piece of LabView software.

6.1. Data Acquisition Electronics. A block diagram of sensor electronics and signal processing is presented in Figure 10.

The emitter is driven by a power operational amplifier. The OP drives a $2 \mathrm{kHz}$ AC current through the platinum heater meander of the MEMS IR emitter. This AC powering is used to avoid electro-migration-induced heater degradation [23]. This AC drive current in turn is modulated with a low frequency ramp signal to produce low-frequency modulated IR light $(5 \mathrm{~Hz})$. The current through the emitter and the voltage across the emitter were sensed. From both quantities the electrical power input into the emitter and thereby the IR light output can be determined. The sensor electronics consists of four identical blocks for the four optical channels. Each channel contains a voltage follower, followed by a high-impedance amplifier and a low pass filter $(\mathrm{fc}=20 \mathrm{~Hz})$ on the output side. The filter embraces the modulation frequency of the MEMS IR emitter. A temperature sensor was embedded in the thermopile array package. All signals were acquired through a USB data acquisition module from National Instruments. A LabVIEW (National Instruments, Austin, TX) program was developed for signal processing.

The thermal IR emitter in this detector system is modulated with a frequency of $5 \mathrm{~Hz}$. The four thermopile receivers on the opposite side will therefore produce four approximately sinusoidal output voltages $V_{3875 \mathrm{~cm}^{-1}}, V_{3660 \mathrm{~cm}^{-1}}$, $V_{3480 \mathrm{~cm}^{-1}}$, and $V_{3320 \mathrm{~cm}^{-1}}$, respectively. These output voltages in turn will depend on the amount of IR radiation that is emitted by the thermal IR source on the left and the transparency of the fluid gap (Figure 8). For ensuring a good lifetime of the thermal IR emitter, the sources should not be operated at temperatures above $700^{\circ} \mathrm{C}(973 \mathrm{~K})$. On the 


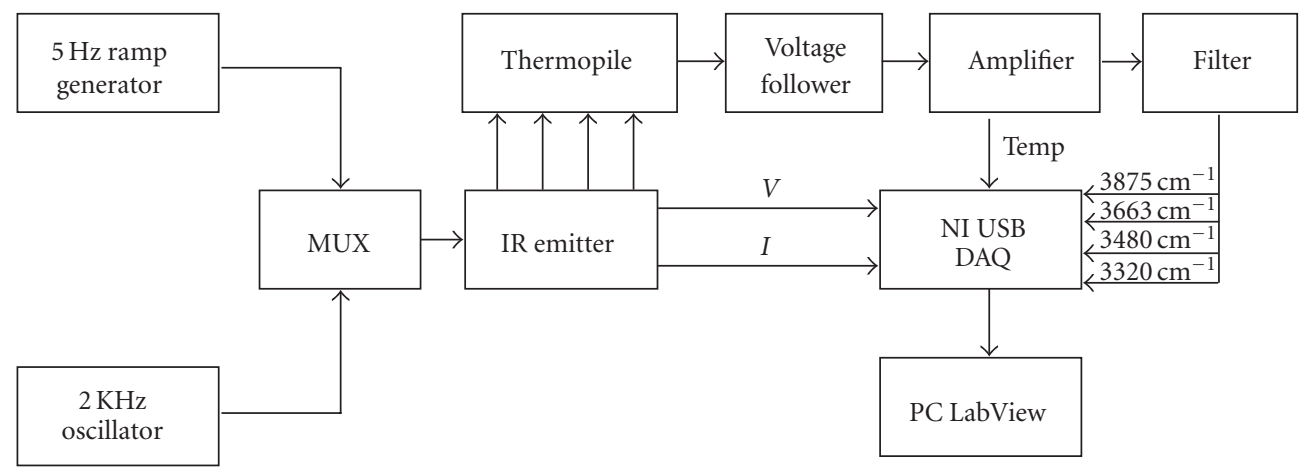

Figure 10: Block diagram of the sensor electronics.

other hand, the amplification on the receiver side should be adjusted in such a way that the AC amplitude at the output of the analogue electronics should not exceed the acceptance range of the follow-on $\mathrm{AD}$ converter $(5 \mathrm{~V})$ under conditions of full transparency $(\approx 88 \%$ for an empty, i.e., airfilled sensor) or about $65 \%$ for a fluid-filled sensor, that is, $V_{\text {peak }}=5 \mathrm{~V}^{*} 0.64=3.2 \mathrm{~V}$.

\section{Fluid Property Measurements}

With this demonstrator system a number of tests had been performed. Fluids with different water and acid contents were filled into the sensor vessel and the IR transparency of the fluid in the four different spectral windows was measured.

7.1. Water Sensitivity of the Sensor. Figure 11 shows how the transparency in the three channels varies as the water content of the hydraulic fluids is increased. The optical absorption in solids and liquids follows a LambertBeer behavior [24]. This expectation is confirmed by the data of Figure 11: whereas the transparency of the $3500 \mathrm{~cm}^{-1}$ channel rapidly decreases as the water concentration is increased, a slower and closely identical decrease is observed in the two neighbour channels which trace the transparency in the high- and low-energy wings of the $3500 \mathrm{~cm}^{-1}$ absorption feature:

$$
\begin{aligned}
& V_{3480 \mathrm{~cm}^{-1}}\left(C_{\mathrm{H}_{2} \mathrm{O}}\right)=0.587 * \exp \left(-2.10 * C_{\mathrm{H}_{2} \mathrm{O}}(\%)\right), \\
& V_{3660 \mathrm{~cm}^{-1}}\left(C_{\mathrm{H}_{2} \mathrm{O}}\right)=0.764 * \exp \left(-0.98 * C_{\mathrm{H}_{2} \mathrm{O}}(\%)\right), \\
& V_{3320 \mathrm{~cm}^{-1}}\left(C_{\mathrm{H}_{2} \mathrm{O}}\right)=0.689 * \exp \left(-0.99 * C_{\mathrm{H}_{2} \mathrm{O}}(\%)\right) .
\end{aligned}
$$

7.2. TAN Sensitivity of the Sensor. In a second set of experiments the response of the four thermopile channels to artificially degraded (acid) Skydrol LD-4 samples was tested. As indicated in Figures 3 and 7, hydrolysis-induced reaction products add spectral weight to the low energy wing of the $\mathrm{O}-\mathrm{H}$ absorption feature, that is, at $3350 \mathrm{~cm}^{-1}$. In order to test the sensor, several solutions were prepared with TAN values in the range of 0 to $1 \mathrm{mg} \mathrm{KOH} / \mathrm{g}$. As revealed from Figure 12, the difference in the transparency of the $3350 \mathrm{~cm}^{-1}$ and $3650 \mathrm{~cm}^{-1}$ channels scales in a logarithmic fashion as the

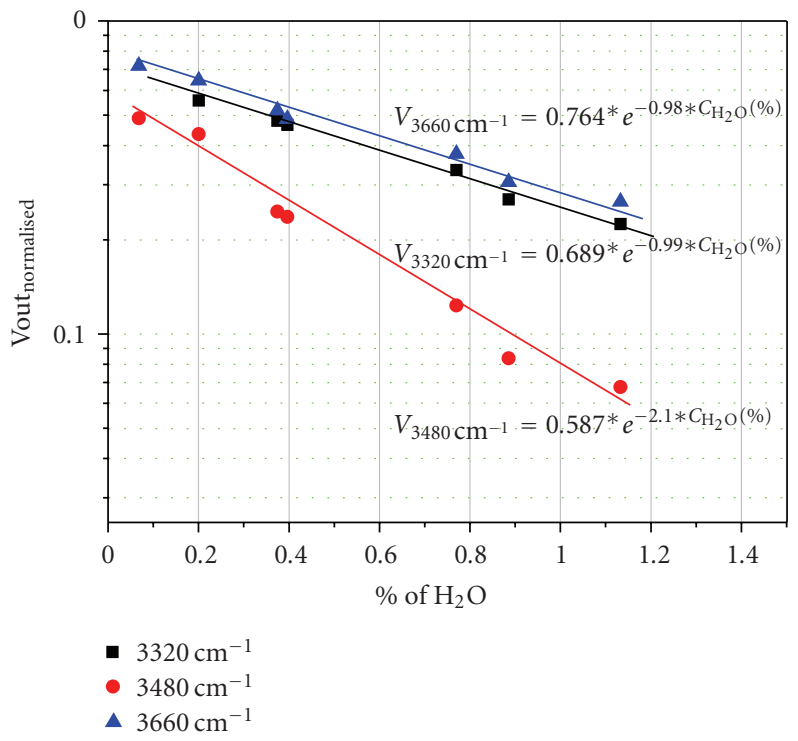

Figure 11: Variation of the thermopile detector output with the water content of Skydrol LD-4. The curve with the steep slope refers to the $3480 \mathrm{~cm}^{-1}$ centre absorption band and the shallower ones to the high- and low-energy absorption bands around $3660 \mathrm{~cm}^{-1}$ and $3320 \mathrm{~cm}^{-1}$, respectively. The output signals were normalized to the $3875 \mathrm{~cm}^{-1}$ reference channel.

TAN value is increased. For larger values of TAN, a saturation of the sensor signal is observed. A quantitative determination of TAN values larger than $1 \mathrm{mg} \mathrm{KOH} / \mathrm{g}$, therefore, is not possible with this sensor principle:

$$
\mathrm{TAN}_{\mathrm{mgKOH} / \mathrm{g}}=\frac{1}{4.772} \ln \frac{\Delta V}{64.7 \times 10^{-3}}
$$

for $0<\mathrm{TAN} \leq 1 \mathrm{mg} \mathrm{KOH} / \mathrm{g}$.

7.3. "Health Plot" of Hydraulic Fluids. Keeping in mind that dissolved water can be removed from hydraulic fluids, but that hydrolysed and acidified fluid needs to be replaced to prevent damage to the hydraulic system, maintenancerelevant information can be retrieved considering the IR transmission in the three spectral windows. In order to retrieve this information, we calculated the difference in 


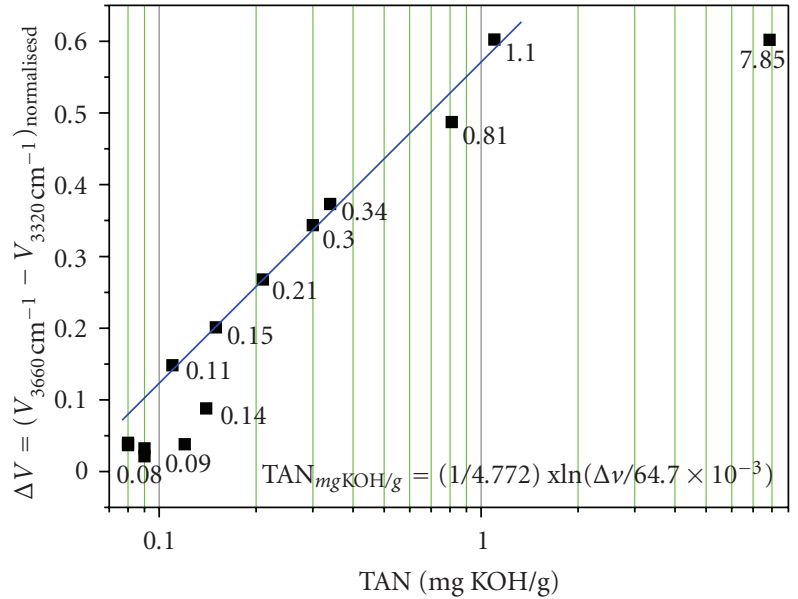

Figure 12: Acid sensitivity of the sensor system. The difference in output signals of the $3660 \mathrm{~cm}^{-1}$ and $3320 \mathrm{~cm}^{-1}$ channels shows a logarithmic dependence on TAN in the range of 0 to $1 \mathrm{mg} \mathrm{KOH} / \mathrm{g}$.

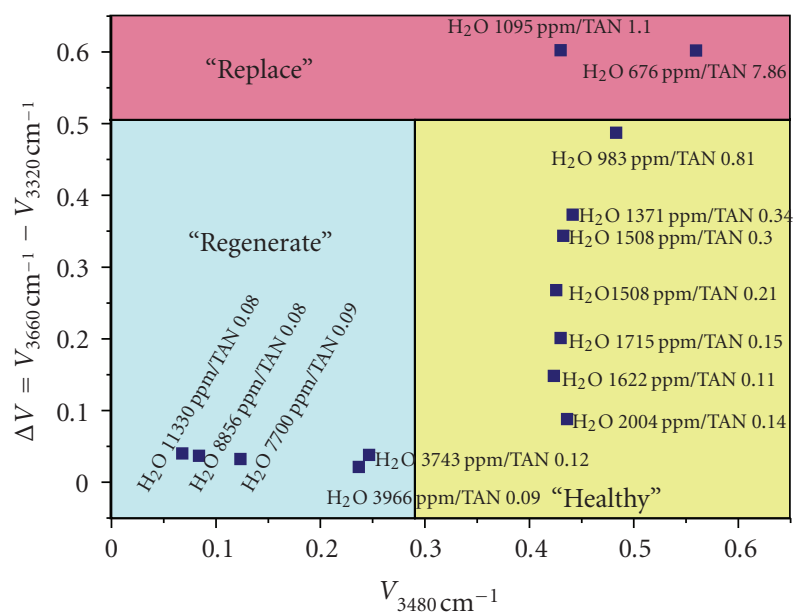

Figure 13: "Health plot" of pure and degraded hydraulic fluids as determined by the NDIR sensor system demonstrator. This is based on the authorized in-service limits (by Airbus), for water and TAN.

transmissions as measured in the $3320 \mathrm{~cm}^{-1}$ and $3660 \mathrm{~cm}^{-1}$ spectral windows, that is, $\Delta V=V_{3660 \mathrm{~cm}^{-1}}-V_{3320 \mathrm{~cm}^{-1}}$ and plotted them as a function of the transmission $V_{3480 \mathrm{~cm}-1}$ in the centre $3480 \mathrm{~cm}^{-1}$ window. This exercise has been done in Figure 13 using the data of Figures 11 and 12.

The data points in Figure 13 can be regarded as twodimensional state vectors that indicate the "health" of the hydraulic fluid. As can be seen from Figure 13, the fluid is "healthy", that is, uncontaminated in case the state vector signifies a high transparency at around $3500 \mathrm{~cm}^{-1}$ and a small asymmetry $\Delta \mathrm{V}$. Addition of dissolved water, that is, water that can be removed by polymeric filters, vacuum distillation or by headspace dehumidification [25], shifts the state vector towards lower values of $V_{3500 \mathrm{~cm}^{-1}}$ with the asymmetry $\Delta \mathrm{V}$ lying close to zero. Fluid degradation, that is, hydrolysis and acidification shifts the state vector to large positive values of $\Delta V$ with $V_{3500 \mathrm{~cm}^{-1}}$ staying at fairly high values. This health plot therefore can be interpreted as a straight-forward way to arrive at relevant maintenance decisions.

\section{Conclusion}

Two important chemical contamination properties, that is, water and acid in phosphate ester hydraulic fluid can be monitored by NDIR absorption. Since NDIR senses localised vibrations of $\mathrm{O}-\mathrm{H}$ groups associated with water and hydrolysis products, the sensor principle is independent of the composition of the base aryl/alkyl phosphate ester fluids. A sensor system is demonstrated for "online" health monitoring of the fluids in aircraft hydraulic systems. The system comprises a broad-band thermal IR emitter, a 4channel thermopile and a tiny fluid channel between the two elements. Commercially available MEMS components were used for the construction. The accessible water detection range $(0-1.5 \%)$ complies with the range of water contaminations that can appear in the practical aircraft operation. The accessible TAN detection range (0-1 $\mathrm{mg} \mathrm{KOH} / \mathrm{g})$, however, is somewhat smaller than the maximum allowed TAN value of $1.5 \mathrm{mg} \mathrm{KOH} / \mathrm{g}$ (for Airbus aircraft). The detection limit is dependent on the length of the optical absorption path. This limit can be slightly increased by narrowing the optical path.

Further development work is underway to install the sensor system in an aircraft hydraulic system. This will require construction of a mechanical manifold with sapphire optical windows that is sufficiently strong to sustain the pressures ( 200-400 bar) inside an aviation hydraulic system.

\section{Acknowledgments}

This project was partially funded by Airbus, Eurocopter, EADS, and then by the European Union under the FP6 project "SuperSkySense". The authors wish to express their special thanks to S. Biermann and P. Sachse from MicroHybrid Electronic GmbH, Germany, for their support with specialized thermopile arrays. Support from Dr. Käpplinger of Siegert TFT, Germany, with optical filters is also acknowledged. Thanks also go to Hechtenberg who assisted us in the construction of the sensor electronics.

\section{References}

[1] G. E. Totten, Handbook of Lubrication and Tribology: Application and Maintenance, CRC Press, Boca Raton, Fla, USA, 2006.

[2] D. A. Lombardo, Advanced Aircraft Systems, TAB Practical Flying Series, McGraw-Hill, New Delhi, India, 1993.

[3] C. Bauer and M. Day, "Water contamination in hydraulic and lube systems," Practicing Oil Analysis Magazine, vol. 9, no. 910, 2007.

[4] J. P. Richard, Advances in Physical Organic Chemistry, Academic Press, New York, NY, USA, 2006.

[5] D. Wooton, "The lubricant's nemesis-oxidation," Practicing Oil Analysis Magazine, vol. 9, no. 5-6, 2007.

[6] N. Robinson, "Monitoring oil degradation with infrared spectroscopy," Practicing Oil Analysis Magazine, vol. 9, no. 1112, 2007. 
[7] M. J. Adams, M. J. Romeo, and P. Rawson, "FTIR analysis and monitoring of synthetic aviation engine oils," Talanta, vol. 73, no. 4, pp. 629-634, 2007.

[8] A. Lambrecht, S. Hartwig, J. Herbst, and J. Wöllenstein, "Hollow fibers for compact infrared gas sensors," in Photonic Crystal Materials and Devices VII, vol. 6901 of Proceedings of SPIE, January 2008.

[9] K. Katarzyna, P. Andreas, and A. W. Koch, "Development of an infrared sensor for on-line analysis of lubricant deterioration," in Proceedings of the IEEE Sensors, vol. 2, pp. 903-908, 2003.

[10] J. R. Powell, "Molecular condition monitoring in the commercial world: objectives and applications of FT-IR analysis," Tech. Rep. A096743, Bio-Rad Laboratories, Cambridge, Mass, USA, 1998.

[11] B. W. Wilson, N. H. Hansen, and T. J. Peters, Modular System for Multi-Parameter In-Line Machine Fluid Analysis, Pacific Northwest National Laboratory, Richland, Wash, USA.

[12] T. Krist, Hydraulik Fluidtechnik, Vogel Buchverlag, Wurzburg, Germany, 1987.

[13] L. R. Rudnick, R. L. Shubkin, and R. R. Rudnick, Synthetic Lubricants and High-Performance Functional Fluids, Marcel Dekker, New York, NY, USA, 1992.

[14] G. E. Totten, Handbook of Hydraulic Fluid Technology, Marcel Dekker, New York, NY, USA, 1999.

[15] “Aviation lubricants," http://www.exxonmobil.com.

[16] Technical bulletin, "Skydro l- Type IV fire resistant hydraulic fluids, LD-4/500B-4," Pub. no. 7249153C (Supersedes 7249153B), http://www.skydrol.com.

[17] D. Oesterle and The Lubrizol Corp.Wickliffe, "Ohio Hydraulic Fluid: Pay Now or Pay Later,” Hydraulics \& Pneumatics, 2006, http://www.hydraulicspneumatics.com/.

[18] P. A Schweitzer, L. R. Rudnick, and R. R. Rudnick, Lubricant Additives: Chemistry and Applications, Marcel Dekker, New York, NY, USA, 2003.

[19] P. Capper and C. T. Elliott, Infrared Detectors and Emitters: Materials and Devices, Kluwer Academic Publishers, Dordrecht, The Netherlands, 2000.

[20] A. Rogalski, Infrared Detectors, CRC Press, Boca Raton, Fla, USA, 2000.

[21] M. Henini and M. Razeghi, Handbook of Infrared Detection Technologies, Elsevier, Amsterdam, The Netherlands, 2002.

[22] G. S. Brady, H. R. Clauser, and J. A. Vaccari, Materials Handbook: An Encyclopedia, McGraw-Hill, New Delhi, India, 2002.

[23] B. K. Liew, N. W. Cheung, and C. Hu, "Electromigration interconnect lifetime under AC and pulse DC stress," in Proceedings of Symposium on VLSI Technology, pp. 59-60, San Diego, Calif, USA, May 1988.

[24] K. J. Laidler, The World of Physical Chemistry, Oxford University Press, Oxford, UK, 1995.

[25] J. J. Pippenger, Tyler Gregory Hicks, Industrial Hydraulics, McGraw-Hill, New Delhi, India, 1979. 

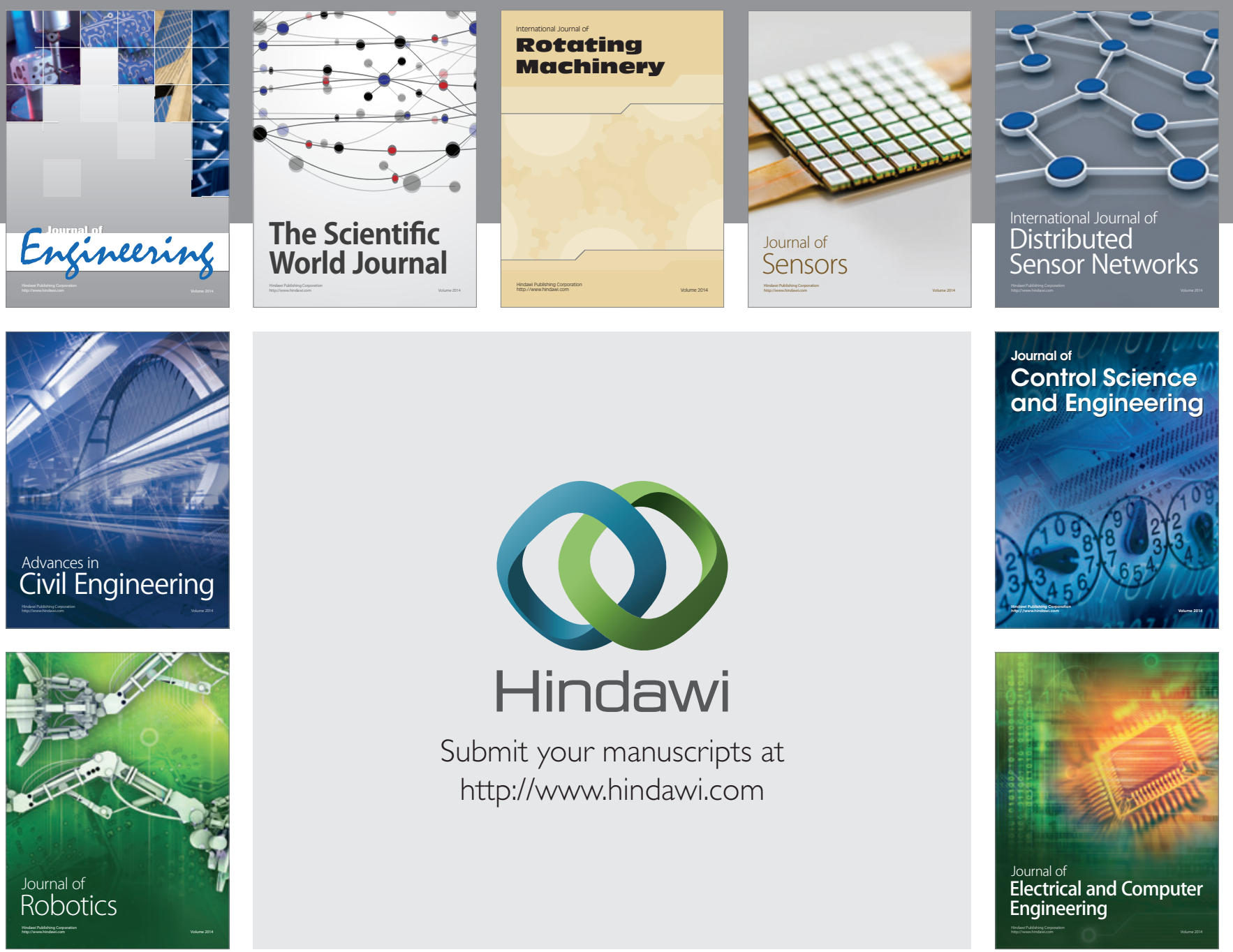

Submit your manuscripts at

http://www.hindawi.com
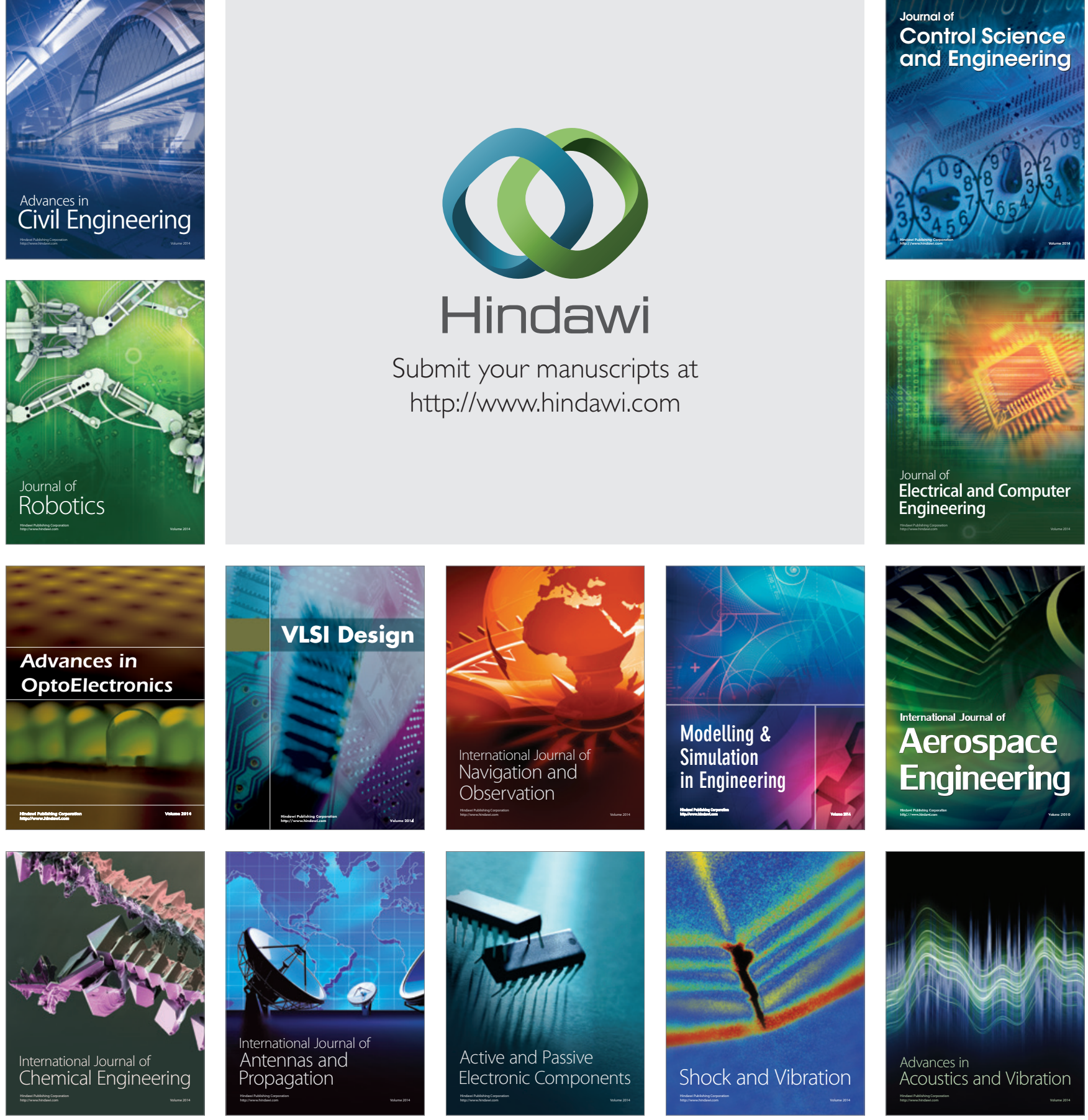